\title{
A Study of the Difficulties in Learning of English Faced by Hindi and Urdu Speaking Students in India and Indian Expatriates in Saudi Arabia
}

\author{
Qudsia Iqbal Hashmi ${ }^{1, *}$ \\ ${ }^{1}$ CCS University, Meerut, India \\ *Correspondence: CCS University, Meerut, India. E-mail: iqbalqudsia@yahoo.co.in
}

Received: September 2, 2016 Accepted: September 21, 2016 Published: November 13, 2016

doi:10.5296/ije.v8i4.10292 URL: http://dx.doi.org/10.5296/ije.v8i4.10292

\begin{abstract}
Main aim of the study was to explore and analyze the learning difficulties faced by Hindi and Urdu speaking-students in India and Indian expatriates in Saudi Arabia. It is generally felt that learning of English varies in different context. Learners having background of Urdu, Hindi differ on account of learning achievements. Similarly those who enjoy more English learning environment may perform better than their counterparts. In order to carry out the study, three types of subjects were purpose. The study, though was descriptive-qualitative in nature, quantification was used to arrive at statistical inferences. The results indicated that most of the learner's problems arose due to L1 interference on second language learning process.
\end{abstract}

Keywords: English as a second language (ESL), learning difficulties, interference, learning environment, teaching strategies. 


\section{Introduction}

India has officially recognized the importance of English, giving it the constitutional status of 'Associate Official Language'. This status has changed and altered under political and social pressures in a vibrant society with a democratic structure and due to the presence of many cultures, languages and religions. By and large, it is enjoying the status of second language in India. (Khan, 2011, 1248-1257)

English, which had an 'elite' and somewhat alien status during the Raj in India has now grown and assumed the status of a compulsory link language, the lingua franca. At the most important sphere of language acquisition: education in general and school education in particular, it has been gradually adopted as a subject, field of study and most importantly the medium of instruction and examination. It is the medium of instruction in many schools and functions as the first, second language at secondary and senior secondary levels. Higher education in the metros and larger and smaller towns is invariably in English.

Studies on learners' language programmes are important as they are based on empirical classroom experience. Hence they provide genuine feedback to instructors as well as instructional designers to create need-based programmes that would benefit different learner types and enhance their efficacy and competence. Social disparities increase these variations as in the variation in learners' exposure to English language and their socio-economic experiences lead to the difference in their learning. (Khan, 2015, 1-9)

Even years of exposure to English language teaching in school fail to bring them up to acceptable standards of the language in many schools. The case of Urdu/Hindi speakers studying in different schools bears greater significance in this context. Such learners remain deficient in using the English language even in ordinary day-to-day communication. This problem is becoming more acute because India's rapidly growing technologically advanced economy demands a large number of students to pursue professional, technical and academic programmes which clearly require appropriate knowledge of the target language- English. It is felt by most pedagogues that traditional teachings and sheer translations of the concerned texts are not the obvious solution to these problems, as later they would require adequate grasp of the language to communicate in the work environment as well.

This study intends to present a thesis on a comparative analysis of the difficulties faced in the learning of English language by Hindi- and Urdu-speaking students in India and Indian expatriates in the Kingdom of Saudi Arabia (KSA). The differences and similarities (if any) encountered by the teachers while dealing with various aspects of English Language Teaching (ELT) in the system of formal schooling of, children of Indian expatriates, in KSA and in India have been focused. To be able to undertake such an analytical study, the researcher has embarked upon a two-stage field work: collecting materials and information from both KSA and India, including personal visits to schools for purposes of observation and distributing carefully planned questionnaires to both teachers and students in the target schools in both countries. The aim has been nothing but to get a neutral perspective on the subject to evaluate honestly, analyze the data accordingly, and come up with suggestions and reparative measures to address the difficulties faced by the students due to various reasons. 
An obvious difference between the two languages under study here is their different word orders due to their respective roots. The Hindi language and its grammatical structure are derived from Sanskrit. In Hindi, as in some European languages like French, the rules for the conjugation of verbs are quite different from those in English. Belonging to different families of languages, namely the Indo-Aryan and the Anglo-Saxon, these differences are bound to be dissimilar. Hence, there is a basic difference in the order in which words are used in both languages. In Hindi, the normal order of words can be: Subject, Object and Verb (S-O-V). In some cases people are found using the following pattern as well: Subject, Verb and Object $(\mathrm{S}-\mathrm{V}-\mathrm{O})$. However, English being bound to follow its rule of the sentence structure, does not usually allow any change in the order of the Subject, Verb and Object (S-V-O).

\subsection{Indian Expatriates and Learning English in Saudi Arabia}

Schools are the main vehicle for learning English in KSA as elsewhere where it isn't the first language. Despite the fact that Indian schools in KSA are operational in its local socio-cultural setting, teaching-learning of English is not much affected within the educational setting of the Indian schools.

\subsection{Rationale for the Study}

Students of different background can face different types of difficulties in the process of learning English. They can commit specific mistakes in learning English pronunciation, grammar, spelling, meaning and vocabulary usage. There is a close connection between the mother tongue of a learner and specific difficulties in learning and the kind of errors a learner typically commits. (Lado, 1957)

The above issue contributed a lot in the conception of research question of the present study.

\subsection{Research Questions}

I have equated the learning difficulties faced by the Hindi/Urdu speakers studying English in India with those who are Indian expatriates and pursuing English in KSA. Therefore, the questions conceived are:

1- Do the second language learners of English face problems in India and KSA?

2- Do these students face difficulties due to their first language background?

3- Are there other reasons of such difficulties?

\subsection{Statement of the Problem}

The purpose of studying in detail the errors that repeatedly occur in the learning of English as a Second Language by primarily Hindi-speaking learners is to focus on the process of learning. Most research work studies the errors in grammar and syntax (for example, the difference in word orders in the two languages) that occur while learning second languages, but while doing this, they do not reflect upon or highlight the effect of the learners' individual socio-economic background or linguistic orientation. They also fail to focus on other important factors such as gender and cultural influences that pose hindrances in the learning 
of English as a Second Language.

The ultimate aim of this research is to shed light on these problems so that proactive measures can be taken to improve the curriculum and teaching methodology, while taking cognizance of the needs of the specific target learners. This will serve to make the whole learning process more effective and realistic. It also hopes to open up avenues for further research along those lines that have not been taken up in the present research but have been suggested, which holds true especially in this area of academic research that is yet largely uncharted.

\subsection{Objectives}

1. To examine the use of English as First, Second or Third Language in the school curriculum as defined by various agencies of the state apparatus.

1. To examine the issues that might have been overlooked while designing the curriculum for the teaching of English in the non -English-speaking world.

2. To study the processes of learning English in India against the backdrop of societal changes and other relevant factors.

3. To examine whether it is English per se that poses a threat to the native languages and cultures or whether there are other elements that have become accessible through English threatening the indigenous socio-cultural fabric?

\subsection{Sample}

Three schools were selected based on the medium: Hindi, Urdu and English speaking students. In this research, the focus was on three types of schools which were Hindi, Urdu and English medium respectively.

\subsection{Research Methodology}

The present study will involve qualitative research methodology. Qualitative research employs analytic induction and emphasizes on causes, interpretations and implications. (Miles \& Huberman, 1994.) Before making progress in any field, scholars must possess description of the phenomenon with which they want to work. The objective of descriptive research is the determination of the prevailing conditions, practices and attitudes and seeking accurate descriptions of activities, objects, processes and persons. This domain of qualitative research is not confined to data gathering alone but includes the identification and clarification of relationships among variable categories. Descriptive data are usually collected by administering questionnaires, interviewing subjects, observing events or analyzing documentary sources. (Dalen and Diabold, 1979)

\subsection{Tools Used}

The proposed tools to be used in this empirical study are:

(a) Learners' Notebooks, Test/Examination scripts, Essays and Compositions to test the comprehension capabilities of learners and their ability to assimilate and reproduce 
information, build upon thoughts and ideas and the ability to communicate them through creative expression.

(b) Teachers' corrections marked in the above scripts and comments/remarks given by the teachers on the scripts or in the report cards to see if they are able to provide valid feedback and guidance to learners. This information can then be used to make suggestions for improvement in pedagogical techniques.

(c) Specifically designed assignments, quizzes and questionnaires to test the linguistic capabilities and competence of learners. These would include exercises in sentence correction, use of the correct words, situational questions based on everyday experiences and encounters.

(d) The actual subjects of study, i.e., the students whose work and experiences are to be studied (the figure given - 180 students of government schools in Delhi-may be adhered to or changed as per the scope of the present study).

(e) The prescribed syllabus for Grade V is chosen as it is a standardized syllabus across all schools.

Hence the purpose and purview of this study is to analyze empirically and in detail the errors that occur in the learning of English as a Second Language by native speakers of Hindi in order to look for the reasons for these errors so that efforts and suggestions may be made to introduce new and more effective pedagogical tools and techniques to improve teaching and learning of English as a Second Language.

(f) Teacher's questionnaires

This self developed tool is expected to elicit the teachers' perception of learning difficulties and possible reasons. This will add to the findings based on the data gathered through the students' sheets and tests.

\subsection{Analysis and Interpretation}

The data will be analysed and results will be interpreted in accordance with the objectives, tools and nature of the study.

\section{Critical analysis of Pedagogic Issues}

\subsection{Teaching English Language and Errors Encountered in the Process}

The second/foreign language learners usually face various kinds of difficulties in the learning of English. The areas of difficulties may range from aspects to skills. The following is a description of learning difficulties in skills: listening, speaking, reading and writing.

\subsubsection{Problems in learning 'listening'}

The specific problems that teaching listening bring are not self-evident. And although research on the skill is limited, some valuable sources offer valid comments on the problems 
involved in teaching listening.

Despite its obvious importance to language learning, the listening skill has always been an ignored phenomenon.

With the emergence of communicative language teaching and the focus on ability, proficiency, and skills, the learning and teaching of listening received more attention. However, listening is not yet an integral part in most of the Indian classroom setting.

\subsubsection{Difficulties in speaking}

The learners are found facing difficulties in speaking on account of sound, accent, dialect etc. The importance of teaching speaking has always been felt as the most important productive skill. In a second/foreign language learning situation, neither teachers nor the students spend enough time for the learning and practice of speaking skills for many reasons. In addition, the learners neither possess enough vocabulary nor structure to communicate in the target language.

As mentioned earlier the target language teacher focus especially on teaching grammar (for the sake of grammar)and vocabulary items (usually passive) rather than teaching skills in general and speaking in particular. Both of the communicative focused and unfocused tasks one has to engage learners in using language pragmatically rather than displaying language. They seek to develop language proficiency through communication.

\subsubsection{Problems in Learning Reading}

There are two types of problems in learning reading. Basic reading problems occur when there is difficulty understanding the relationship between sounds, letters and words. Reading comprehension problems occur when there is an inability to grasp the meaning of words, phrases, and paragraphs. Signs of reading difficulty include problems with:

- letter and word recognition

- understanding words and ideas

- reading speed and fluency

- general vocabulary skills

Teaching reading can be an arduous task as it is often difficult to know how to improve students' skills. There are different types of reading skills:

- Skimming — reading rapidly for the main points

- Scanning - reading rapidly to find a specific piece of information

- Extensive - reading a longer texts, often for pleasure with emphasis on overall meaning

- Intensive reading - reading a short text for detailed information

These different types of skills are used quite naturally when reading in a mother tongue. 
Unfortunately, when learning a second or foreign language, people tend to employ only "intensive" reading skills. It is often noticed that students insist on understanding every word and find it difficult to take any advice of reading for the general idea, or when they do read longer tracts, it is often only to look for specific information. Students studying a foreign language often feel that if they don't understand each and every word they are somehow not completing the exercise.

In order to make students aware of these different types of reading styles, the teacher is required to help them identify reading skills that they already apply when reading in their native tongues. Thus, when approaching an English text, students need to first identify what type of reading skill has to be applied to the specific text at hand. In this way, valuable skills, which students already possess, are easily transferred to their English reading.

The use of contextual clues can be one of the best ways to improve students' reading skills. Unfortunately, students often insist on understanding each word when reading. Realizing that a text can be understood in a general sense by using contextual clues can go a long way towards helping students cope with increasingly difficult texts. At the same time, the use of contextual clues can also provide a means by which students can rapidly increase their existing vocabulary base.

\subsubsection{Problems in Learning Writing}

Children go through several language development stages: toddlers start learning to write in kindergarten, when they are often given a series of story cards to arrange in order. In early elementary, the focus is on teaching motor skills and the writing process. By middle school, students are expected to know how to write, and write well. If they do not possess these tools, their schoolwork suffers. For instance, middle school classroom work and student homework in subjects such as science and history require students to first interpret what they read. Then they are often asked to write on-the-spot essays.

Learning difficulties in writing can involve the physical act of writing or the mental activity of comprehending and synthesizing information. Basic writing disorder refers to physical difficulty in forming words and letters. Expressive writing disability indicates a struggle to organize thoughts on paper. Symptoms of a written language learning disability revolve around the act of writing. They include problems with:

-neatness and consistency of writing

-accurately copying letters and words

-spelling consistency

-writing organization and coherence

\section{Literature Review}

The review of the international studies reveals that there are so many issues associated the learning difficulties faced by the target learners in the process of learning English as a second language. It was found that code-switching that can be described as the linguistic use of two 
or more languages in a single conversation where the speakers use or at least perceive the language into which switching occurs. In the same context, some studies indicate that ELF speakers who face the challenges of managing difference in communication as they come from different linguistic and cultural backgrounds.

This situation is best analysed by Bernstein (1971): Not only the pupils come from different linguistic backgrounds but the same situation prevails in case of teachers. Both of them have exposure to English outside the class room.

It was also concluded by some researchers that Second language learners often make systematic errors in grammar, and these errors are usually based upon their first language. A study describes the academic English language proficiency of immigrant youth after, on average, 7 years in the United States and models factors that contribute to variation. Findings show that although differences in individual student characteristics partially explain variation in English language proficiency, the schools that immigrant youth attended are also important.

Thus, a complete idea regarding learning difficulties was developed in the area of phonology, morphology semantics, lexicon and syntax which surely help the present researcher to carry out her study.

Khan (2003) hypothesized that there was no significant difference between Urdu and Hindi speaking students in terms of difficulties while English as a second language. The main objectives of his study were:

1. To ascertain the extent to which the Urdu and Hindi speaking students faced difficulties in learning English as a second language with special reference to the English grammar, sound systems, vocabulary, spelling and close items in addition to causes attributed to such difficulties.

In their article titled, 'Challenges and Strategies for Teachers and Learners of English as a Second Language: The Case of an Urban Primary School in Kenya' (2013), Dhillon and Wanjiru take up an urban multilingual primary school in Kenya while looking at the many problems surrounding the acquisition of English as a second language both at the level of the teachers as well as the learners. Focusing not so much on the content as on the form of teaching, the researchers highlight the very struggle that goes into changing their way of lives in order to facilitate a more fluid comprehensive adoption of the language.

Research indicates that teaching students specific strategies to acquire English as a second language is positively influenced by comprehension of concepts and encouragement of critical faculty rather than by-rote learning and grammatical and syntactic approaches. One important model for ESL acquisition is CALLA (Cognitive Academic Language Learning Approach). This means using learning strategies, age appropriate text, development of language tools, and overall expansion of knowledge rather than specific learning while using English, is much more effective than traditional teaching theories.

It was also found that 'Bilingual learning' poses a greater challenge than the learning of 
English by native speakers as has become apparent from our discussion in the previous chapter. Using English regularly and consistently and not the mother tongue as the medium of instruction can be a reparative measure to counter this problem. However, it could also be argued that better nonverbal intelligence is not represented in performance-oriented education and, therefore, the gap between learning and knowledge may be more than what is otherwise perceived to be. The factors responsible for the level and types of difficulties also vary from case to case. However, among the prominent factors, the following are some:

-Socio-cultural background,

-Language background,

-Mother-tongue interference,

-Teaching methodology,

-Teacher management

-Textbooks etc.

Agnihotri $(1995,3)$ suggests some reparative measures to assist language learning in a multilingual classroom: in order for language learning to be successful, the situation needs to be informal; the learner should be free from any anxiety; the teacher should essentially be a friend, observer and facilitator; and most of the learning process should be centred on meaningful tasks and peer-group interactions. Snowden (2007, p.308) points out that 'the qualities in a teacher are key to overall success in the classroom, although concern with the latest techniques and methods has tended to obscure this fact'. Ken Hyland $(2003,186)$ provides a detailed formulation of which errors to target while providing feedback to learners in order to improve students' written English related to genre specific, stigmatizing, comprehension, frequency and so on.

Armendaris in "Writing Anxieties among English as a Second Language Students Enrolled in Academic English Writing Classes" (2009) takes up the question of learning English as a second language (ESL) on an academic level and raises the following three important questions. Firstly, what are the common roadblocks faced by students in the learning process; secondly, the role played by the teaching methodology employed by teachers and its positive as well as negative implications. However, studies have shown that the pragmatic strategies used by ELF speakers include code-switching which is not considered a sign of lacking language knowledge but instead a strategy that shows creative use of pluro-lingual resources to enable communication" (Cogo, 2009).

"The development of students' L2 writing can be influenced by multiple factors such as L1 writing ability, L2 proficiency, and writing experiences in both languages (Kobayashi \&Rinnert, 2008).

Kecskes and Papp (2003) focused on "the influence of L2 on L1 when the L2 is being taught in a relatively homogenous language community where the student does not have access to the target culture. Marsh, Hau and Kong (2000) found that "students in Hong Kong who 
received instruction in both Chinese (L1) and English (L2) had stronger L1 skills. The study, which looked at late immersion, also found negative effects on performance in History, Geography and Science, all taught in the L2. These findings may well demonstrate the need for appropriate L2 proficiency and support before content learning begins in the L2.

Having reviewed the above mentioned national/Indian and International studies and literature, it can be concluded that the learners of the second/foreign language (English) face variety of difficulties and challenges in the learning process. The review of the above significant investigations indicated that spellings, vocabulary, sentence structure and comprehension are major areas in language which need special attention.

\section{Data Collection, Analysis and Interpretation}

\subsection{Data Collection}

\subsubsection{Assessment- 1}

As opposed to a proficiency test, a diagnostic test is not aimed at judging how good one is at the application of a language on a comparative basis but rather to diagnose the problems that a person faces in learning and using that language, which was primary aim in designing the following test which is an objective assessment included a set of fourteen different tests covering the following:

Identification of correct letter, incorrect words, Spellings test using homophones, Synonyms-Antonyms test, Sentence identification, Word arrangement, Singular/Plural test, Tenses test, Pronunciation test using homophones, Word-Meaning test etc.

Not only will be presented a detailed analysis of the performance of the students in the above-mentioned tests, but also a comparative analysis of Hindi and Urdu speaking students will be done according to the main focus of my study.

\subsubsection{Assessment-2}

In an attempt to observe the creative skills of student when it comes to the application of the second language in writing, my second assessment was primarily a test on their writing skills. It comprised questions on writing a paragraph on the best movie that you have seen. Why did you like it so much? Or 'My Birthday Party'.

A comparative analysis of the performance of the students (3 groups) in the above mentioned test was done separately and on the whole. Data collection is a hectic process, but due to the fact that my sister teaches at Jeddah-KSA, it was possible to collect data. The two schools in India were located in the south Delhi, Jamia Nagar locality where he researcher resides. So these data were also gathered in time. A prior permission to conduct the tests was sought from the school administration.

\subsection{Data Analysis}

The following is a comparative analysis of the performance of the students from Hindi, Urdu 
and English medium schools based on the data obtained.

\begin{tabular}{lll}
\hline $\begin{array}{l}\text { Number of Urdu medium } \\
\text { students }(\mathrm{U}):\end{array}$ & $\begin{array}{l}\text { Number of Hindi medium } \\
\text { students }(\mathrm{H}):\end{array}$ & $\begin{array}{l}\text { Number of English medium } \\
\text { students at DPS (E): }\end{array}$ \\
\hline 80 & 70 & 48 \\
\hline
\end{tabular}

\subsubsection{Comparative analysis}

Table 1. Marks of the students

\begin{tabular}{lllllllll}
\hline Groups & \multicolumn{2}{l}{ Average marks of students (correct answers) } \\
\cline { 2 - 9 } & spelling & $\begin{array}{l}\text { Spelling } \\
\text { (homophone) }\end{array}$ & Synonym & antonym & number & meaning & $\begin{array}{l}\text { Word- } \\
\text { choice }\end{array}$ & Total \\
\hline Urdu & 57.3 & 42 & 29 & 47.5 & 51.3 & 30.6 & 23 & $\mathbf{3 9 . 9 \%}$ \\
Hindi & 39.4 & 35 & 8.6 & 25.8 & 25.2 & 14.2 & 37.2 & $\mathbf{2 6 . 4}$ \\
English & 70.05 & 81.6 & 79 & 91.5 & 82.5 & 52.35 & 51 & $\mathbf{7 2 . 5}$ \\
\hline
\end{tabular}

\subsubsection{Analysis of the teachers' questionnaires}

The following table shows the responses of the questionnaire administered on the English teachers.

Table 2. Number of responses

\begin{tabular}{|c|c|c|c|c|}
\hline $\mathrm{SN}$ & Statements & Agree & undecided & Disagree \\
\hline 1 & & 29 & 5 & 6 \\
\hline 2 & & 27 & 6 & 7 \\
\hline 3 & & 33 & 3 & 4 \\
\hline 4 & & 26 & 5 & 9 \\
\hline 5 & & 21 & 6 & 13 \\
\hline 6 & & 20 & 4 & 16 \\
\hline 7 & & 19 & 7 & 14 \\
\hline 8 & & 20 & 7 & 13 \\
\hline 9 & & 23 & 5 & 12 \\
\hline 10 & & 18 & 7 & 15 \\
\hline 11 & & 22 & 6 & 12 \\
\hline 12 & & 24 & 5 & 11 \\
\hline 13 & & 23 & 7 & 10 \\
\hline 14 & & 22 & 5 & 13 \\
\hline 15 & & 29 & 4 & 7 \\
\hline
\end{tabular}




\section{Macrothink}

The data show that most of the teachers agree that teaching/learning of English is not an easy task. The teachers are of the view that the learners face varied sort of difficulties in the learning of English as well as the elements of English language. The responses also show that learning environment in side school as well as outside should be appropriate enough. The effect of L1 is undisputable, however, direct method may not always be the right method of teaching in a specific condition.

The graph shows the trend:

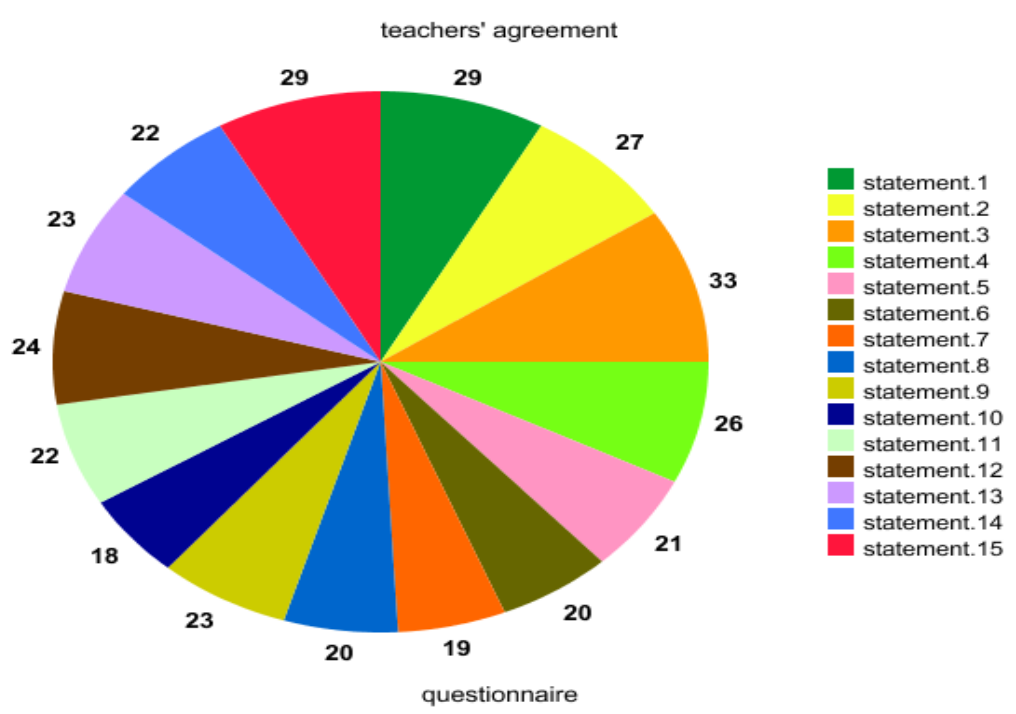

Figure 1. Teachers' Perception

\section{Research Questions and Results}

I have equated the learning difficulties faced by the Hindi/Urdu speakers studying English in India with those who are Indian expatriates and pursuing English in KSA, therefore, the questions conceived are:

1- Do the second language learners of English face problems in India and KSA?

The findings show that all the three groups face problems in the learning of English in Indian schools as well as international schools in KSA where Indian students pursue their CBSC affiliated courses. However, the nature of difficulties and the level varies from context to context. There is a detailed description of the types and amount of difficulties faced by the target groups( in the chapter of analysis).

The overall result has been summarized as under: 
Table 3. Overall Results

\begin{tabular}{|c|c|c|c|c|}
\hline S.N. & $\begin{array}{c}\text { CATEGORY } \\
\text { TEST } \downarrow\end{array}$ & $\begin{array}{c}\text { NO. OF } \\
\text { CORRECT } \\
\text { ANSWERS } \\
\& \%(\text { HINDI)* }\end{array}$ & $\begin{array}{c}\text { NO.OF } \\
\text { CORRECT } \\
\text { ANSWERS \% } \\
\text { (URDU)* }\end{array}$ & $\begin{array}{l}\text { No. of correct } \\
\text { Answers \& \% } \\
\text { (DPS)* }\end{array}$ \\
\hline 1. & Identification of correct letter test & $502(47.8 \%$ & $835(69.58 \%$ & $633(87.91 \%$ \\
\hline 2. & Correction of incorrect words & $261(24.85 \%$ & $548(45.67 \%$ & $588(81.66 \%$ \\
\hline 3. & Spellings test using homophones & $433(41.2 \%$ & $631(52.58 \%$ & $584(81.11 \%$ \\
\hline 4. & Synonyms test & $73(6.9 \%$ & $284(23.67 \%$ & $496(86.11 \%$ \\
\hline 5. & Antonyms test & $223(21.23 \%$ & $456(38 \%$ & $527(91.49 \%$ \\
\hline 6. & Sentence identification test & $403(38.38 \%$ & $665(55.41 \%$ & $596(68.98 \%$ \\
\hline 7. & Word arrangement test & $185(17.61 \%$ & $541(45.08 \%$ & $801(83.43 \%$ \\
\hline 8. & Singular/Plural test & $329(31.33 \%$ & $610(50.83 \%$ & $595(82.63 \%$ \\
\hline 9. & Tenses test-I & $293(27.90 \%$ & $816(68 \%$ & $654(90.83 \%$ \\
\hline 10. & Tenses test-II & $245(23.33 \%$ & $374(31.16 \%$ & $629(72.80 \%$ \\
\hline 11 & Grammar & & & $474(65.83 \%$ \\
\hline 12 & Pronunciation & & & $262(54.58 \%$ \\
\hline 13 & Vocabulary-I & & & $251(52.29 \%$ \\
\hline 14 & Vocabulary-II & & & $276(57.5 \%$ \\
\hline
\end{tabular}

The results show that the English medium school is performing better than even Urdu medium school which is better than its counterpart-Hindi medium school. Many reasons can be associated with the results out of which is the L1 interference. In addition, school environment also contributes to the better results.

Research question- 2: Do these students face difficulties due to their first language background?

The findings indicate that the type and amount of difficulties faced by the Urdu/Hindi medium students may be attributed to the L1background, because the DPS-Jeddah school students don't face similar level of difficulties. They are rather far better in achievement in the diagnostic test.

Research question-3: Are there other reasons of such difficulties?

Though there are no actual measures used in the study to find out the reason of difficulties, yet it can be categorically said that the teaching environment at DPS-Jeddah is far better than the counterparts: Urdu and Hindi medium students in the two schools chosen from the South Delhi area.

Research question-4: Are there any solutions to such learning difficulties? 
The findings are indicative of the possible solutions. It has been found that the school following English as the medium of instruction, and the overall better environment may lead to far better results. Compared to the Indian scenario, the samples chosen are the students of those schools which do not exactly teach English through English. In addition, home environment is not appropriate for the learning of English. They may be from the first generation learners groups. Thus, the learning becomes troublesome for them. In other words, a better teaching strategy, teacher development, and environment enhancement is the only solution for the Urdu and Hindi medium students who performed poorly in the test.

\section{Discussion}

There are too many observations and only one solution. It cannot be denied that the performance of students from Hindi and Urdu medium schools at basic tests of their understanding of English language was overwhelmingly awful. The students had no understanding of such basic concepts as synonyms, antonyms, punctuation, tenses etc. When expected to write a simple meaningful sentence on their own, almost all the children failed. There is no point for political correctness when a reason is sought and presented as the cause for this unfortunate reality. Young students in Hindi and Urdu medium school cannot speak correct energy. That they do not have enough confidence to speak in that language in the first place, is a different story altogether. The problem lies in the teaching methodology alone. It can be supported by the results of the English medium school located at Jeddah-KSA.

While students from both the schools showed a poor performance, the Urdu medium students were as a matter of fact exponentially better than their Hindi counterparts. It must be reiterated that the socio-economic background of these students was very similar, a conscious attempt on my part to keep the influence of those very important factors the same in both cases. It is interesting to think what could possibly be the reason for this. In my opinion, it is because of the relative dominance of Hindi in the social spectrum. While many say that Urdu is dying a slow death, Hindi is ever-so-strong and good to go. In the Urdu medium school, a need for knowing English language is felt so as to make it a more inclusive educational experience for the students for Urdu alone cannot carry them through today's society. Hindi, on the other hand, has a lot of pride and a sense of antipathy towards the colonial legacy of the English language. Because Hindi has a far greater presence in the society vis-à-vis Urdu, in the school room a basic knowledge of Hindi for the students is considered sufficient for his overall development.

As a result of this, it can be argues that more importance is given to the teaching of English as a second language in Urdu schools as compared to the Hindi one and this research with its extensive details bears testimony to it. The DPS though located at Jeddah where outside environment may not be very conducive, the learners far better performance can be credited to the teachers, methods and over all environments at schools. The issue of socio-economic variations doesn't even contribute to any significance effect because there is no such issue of such status consciousness or problems because in KSA, such factors are not at all significant. However, if one were to talk about both the schools together, it can be concluded that the 
performance of both the groups was shockingly poor, be it Hindi or Urdu. In our schools where English is not the medium of education, this language is a cat that no one wants to bell. The only solution to this problem to change the way in which English is being taught as a second language in Hindi and Urdu medium schools. As mentioned previously in this work in the section dealing with the methods, the translation method is not a good tool for this exercise. Students must not be trained to translate words in their head before they can use them in their sentence. This exponentially reduces the student's proficiency and keeps him forever away from the much sought-after fluency.

The overall impact of one's mother-tongue and connected soci-linguistic variance has been a matter of concern, however learners' performance also depend on psychological factors such as motivation and attitude. Series of work has been done by Khan (2011, 2012, 2014a,b, 2015) support the idea of socio-linguistic interferences and psycho-linguistic impact on the learning of English as a second/foreign language.

It is the need of the hour to adopt the bilingual strategies where a particular concept simultaneously brings to mind the two words for it from the two languages and the speaker can use it without any hesitation. It must be understood that cramming word-meanings, antonyms and complex words can never be the solution to learning a new language.

It is believed among those circles that rote learning can help them to learn how to speak English, a view that must have been discarded a long time ago. It is only through constant practice in reading, writing and speaking that can help a student to fully understand and make use of English language in daily life. Moreover, frequent workshops must be held for the teachers in every school where they must be acquainted with newer and best methods of teaching. It is absolutely important that technology must be brought into the fray and teachers must be taught how to use and include it in their teaching methodology to bring about a more effective and inclusive learning experience.

It is no secret that English plays an important part in the life of every person in today's highly globalized world where it has become a prerequisite for success. Therefore, it is important that English is introduced at as early a stage of school education as possible so that the students can inculcate it when it is easier for them to do so. Orthodox and robust methods of teaching must be done away with and the need to make the students understand exactly what it is that they are dealing with is imperative in both the short and long run. Students must be encouraged from a young age to communicate with each other in English as practice alone is the magic wand to learn English language. There should be greater awareness among the masses and those holding power in the field of education that English today is not an option. I hope, with great optimism, that my thesis would help my country to this end.

\section{Conclusion}

This is a very serious problem which has huge ramifications as far as the future of the students and our education system is concerned. We are all a part of a system that does not allow a child to think for himself. A child is bound by his syllabi and the iron fist of the 
person giving it to him. Not only is there no room for creativity and subjectivity, our teaching methodology focuses entirely on the quantity of education given in terms of time and books, but not on the quality of teaching. The focus is on the number of hours that a teacher is teaching, but not even remotely on the 'what' and the 'how' of the teaching process. While the student's attendance holds supreme importance, his/her interest and 'learning' is a matter of no concern. So long as we hold such a utilitarian and reductive approach to our method of education, the results will continue to be as dismal as they have been in the current research.

\section{Recommendations}

Based on the results and conclusions, following are some of the recommendations:

1- Diagnostic analysis needs to be done by the concerned teachers of English to understand the problems,

2- a comparative analysis needs to be performed to deal with the teaching-learning situations,

3- A proper strategy needs to be evolved to cater to the needs of the bilingual learners of English,

\section{Suggestions for Further Studies}

1- An in-depth study may be conducted to explore the factors associated with the teaching-learning of English in Saudi Arabia,

2- An experimental study may be carried out to see the difference between groups of different kinds,

3- An evolution of teaching strategy (with technology integration may facilitate further to come out with fruitful results.

\section{References}

Agnihotri, R.K. (1995). Multilingualism as a Classroom Resource. In Kathleen Heugh, Amanda Sieruhn and Peter Pluddemann (eds), Multilingual Education for South Africa. Johannesburg: Heinemann.

Bernstein, B. (1971). Class, Codes and Control. London: Paladin. http://dx.doi.org/10.4324/9780203014035

Cogo, Alessia (2009). Accommodating Difference in ELF Conversations: A Study of Pragmatic Strategies. In Anna Mauranen and ElinaRanta (eds.), English as a Lingua Franca: Studies and Findings. Cambridge: Cambridge Scholars Publishing.

Dhillon, J. K. (2013). Challenges and Strategies for Teachers and Learners of English as a Second 
Language: The Case of an Urban Primary School in Kenya. International Journal of English Linguistics, 3(2), 15-20. http://dx.doi.org/10.5539/ijel.v3n2p14

Francesca, A. (2009). Writing anxieties among English as a Second Language students enrolled in Academic English Writing Classes, unpublished doctoral thesis. Claremont, California. UMI No.: 3361800 .

Hyland, Ken \& Fiona Hyland (eds) (2006). Feedback in Second Language Writing: Contexts and Issues. Cambridge, New York: Cambridge University Press. http://dx.doi.org/10.1017/CBO9781139524742

Kecskes, I., \& T. Papp (2003). How to demonstrate the conceptual effect of L2 on L1? Methods and techniques. In V. Cook (ed.), Effects of the Second Language on the First. Clevedon, England: Multilingual Matters: 247-65.

Kelleen, T. (2001). Disputes in Child L2 learning. TESOL Quarterly, 35(2), 257-78. http://dx.doi.org/10.2307/3587648

Khan , I.A. (2014). Teachers' Perceptions of the Significance of Local Culture in Foreign Language Learning. Journal of English Language and Literature, 1(3), 65-70. http://dx.doi.org/10.17722/jell.v1i3

Khan, I. A. (2015). Socio-economic Disadvantage and Compatible Teaching Strategies for English language. International Research Journal of Humanities, Language and Literature, 2(9), 1-9.

Khan, I. A. (2014). Cross-linguistic Issues and Compatible Strategies for Teaching English. Journal of Foreign Languages, Cultures and Civilizations, 2(1), 201-225

Khan, I.A. (2003). Difficulties in English: A Contrastive Approach. Delhi: Rajat publication

Khan, I.A. (2011). Learning difficulties in English: Diagnosis and Pedagogy in Saudi Arabia. Educational Research, 2(7), 1248-1257.

Khan, I.A. (2011). Role of Applied Linguistics in the Teaching of English in Saudi Arabia. International Journal of English Linguistics, 1(1), 105-111. http://dx.doi.org/10.5539/ijel.v1n1p105

Kobayashi, H., \& C. Rinnert (2008). Task response and text construction across L1 and L2 writing. Journal of Second Language Writing, 17(1), 7-29. http://dx.doi.org/10.1016/j.jslw.2007.08.004

Lado, R. (1957). Linguistics across cultures: Applied linguistics for language teachers. University of Michigan Press: Ann Arbor.

Marsh, H. W., K. T. Hau \& C. K. Kong (2000). Late immersion and language of instruction in Hong Kong high schools: Achievement growth in language and non-language subjects. Harvard Educational Review, 70(3), 302-46. http://dx.doi.org/10.17763/haer.70.3.gm047588386655k5

Snowden, C. (2007). Culture and the 'good teacher' in the English Language classroom. ELT 
Journal, 61(4), 304-10. http://dx.doi.org/10.1093/elt/ccm049

\section{Copyright Disclaimer}

Copyright for this article is retained by the author(s), with first publication rights granted to the journal.

This is an open-access article distributed under the terms and conditions of the Creative Commons Attribution license (http://creativecommons.org/licenses/by/3.0/). 